Research Paper

\title{
Comparison of the Control of Nausea and Vomiting among Several Moderately Emetic-Risk Chemotherapy Regimens
}

\author{
Hirotoshi Iihara $^{\circledR}$, Masashi Ishihara1, Hironori Fujii ${ }^{1}$, Chiaki Yoshimi ${ }^{1}$, Maya Yamada ${ }^{1}$, Akio Suzuki 1, \\ Kazuya Yamaguchi ${ }^{2}$, Manabu Futamura ${ }^{2}$, Kazuhiro Yoshida ${ }^{2}$, Yoshinori Itoh ${ }^{1}$ \\ 1. Department of Pharmacy, Gifu University Hospital, Gifu, Japan; \\ 2. Department of Surgical Oncology, Gifu University Graduate School of Medicine, Gifu, Japan. \\ $\square$ Corresponding author: Hirotoshi lihara, dai0920@gifu-u.ac.jp.
}

(1) Ivyspring International Publisher. Reproduction is permitted for personal, noncommercial use, provided that the article is in whole, unmodified, and properly cited. See http://ivyspring.com/terms for terms and conditions.

Received: 2015.08.23; Accepted: 2016.01.24; Published: 2016.03.18

\begin{abstract}
Background: Different antiemetic medications with or without aprepitant are recommended for moderately emetic-risk chemotherapy (MEC) depending on the emetic potential of chemotherapy agents, although the criterion for the use of aprepitant is still unclear. The present study was designed to compare the control of chemotherapy-induced nausea and vomiting (CINV) among several MEC regimens used in the outpatient chemotherapy setting. Materials and Methods: $A$ single center prospective observational study was carried out in 326 patients who received 2,061 chemotherapy cycles from January 2013 to December 2014. Antiemetic medication consisting of two-drug combination of granisetron (day 1 ) and dexamethasone (days $1-3$ ) was carried out in $87.6 \%$ of patients receiving the first chemotherapy cycle. The checklist for CINV was provided to all patients, and the control of CINV was evaluated on the next visit based on the checklist. Complete inhibition of nausea and vomiting during acute and delayed periods were compared among MEC regimens. Results: Two hundred and one patients received the first cycle of chemotherapy, in which the rates of complete inhibition of nausea and vomiting were $87.6 \%$ and $95.5 \%$, respectively, during acute period, and $68.2 \%$ and $92.0 \%$, respectively, during delayed period. There were no significant differences in the control of CINV among oxaliplatin, carboplatin and irinotecan, except for the cyclophosphamide-base regimen.
\end{abstract}

Conclusions: Two-drug antiemetic medication of $5-\mathrm{HT}_{3}$ receptor antagonist and dexamethasone was sufficiently effective for prevention of CINV in most MEC regimens.

Key words: moderately emetic-risk chemotherapy - nausea - vomiting - outpatient cancer chemotherapy.

\section{Introduction}

Chemotherapy-induced nausea and vomiting (CINV) is one of most distressing adverse events during cancer chemotherapy [1]. Several clinical practice guidelines for prevention of CINV have been developed by the American Society of Clinical Oncology (ASCO) [2], Multinational Association of Supportive Care in Cancer (MASCC) [3], National Comprehensive Cancer Network (NCCN, 2015) [4], and Japanese Society of Clinical Oncology (JSCO) [5]. It has been reported that the implementation of the guideline-consistent antiemetic medication greatly improves the control of vomiting [6, 7], although nausea that occurs during chemotherapy remains to be the least favorable adverse drug reaction $[8,9]$.

On the other hand, the antiemetic medication for moderately emetic-risk chemotherapy (MEC) is confusing: According to the guidelines from ASCO (2012), NCCN (2015) and JSCO (2010), two-drug combination of palonosetron (day 1) and dexamethasone (days 1-3) is recommended as the standard antiemetic medication for MEC, but the addition of aprepitant to the standard regimen is an optional choice for MEC with relatively high emetic risk. However, the definition of relatively high emetic risk 
anticancer drugs is vague. JSCO (2010) [5] indicated that aprepitant can be used for patients receiving carboplatin, ifosphamide, irinotecan, and methotrexate, while NCCN (2015) [4] suggested that aprepitant should be added to the standard regimen for select patients with additional risk factors or those who experienced CINV in previous therapy using two-drug regimen. ASCO (2010) [2] merely described that limited evidence supports the addition of aprepitant to the two-drug combination therapy by referring from the report of Rapoport et al. [10], in which aprepitant improves the rate of the complete inhibition of vomiting but not of the complete response in patients receiving oxaliplatin, carboplatin, epirubicin, idarubicin, ifosfamide, irinotecan, daunorubicin, doxorubicin, cyclophosphamide $\left(<1,500 \mathrm{mg} / \mathrm{m}^{2}\right)$ or cytarabine $\left(>1 \mathrm{~g} / \mathrm{m}^{2}\right)$.

To determine whether or not another antiemetic should be added to the standard two-drug antiemetic regimen in patients receiving $\mathrm{MEC}$, the rates of complete inhibition of nausea and vomiting during acute and delayed periods were compared among several MEC regimens under the condition of two-drug antiemetic medication.

\section{Materials and Methods}

\section{Patients}

A total of 326 patients of $>18$-year-old in age received 2,061 cycles of moderately emetic-risk chemotherapy (MEC) regimens in our outpatient chemotherapy clinic during two years from January 2013 to December 2014, in which 201 patients received the first chemotherapy cycle. The exclusion criteria was age under 18-year-old, patients having nausea and/or vomiting due to organic causes such as brain metastasis and tumor infiltration of the bowel or other gastrointestinal abnormality. MEC used in the present study included oxaliplatin, carboplatin, irinotecan, cyclophosphamide, nedaplatin, and bendamustine. These anticancer drugs were used as the single-day regimen in combination with or without multiple treatment with low emetic risk or minimal emetic risk agents. The combination of cyclophosphamide and anthracyclines was regarded as highly emetic-risk chemotherapy (HEC) and excluded from the present study. Pharmacists were in charge of provision of drug information and safety precaution in daily life, and monitoring adverse drug reactions, including CINV, to all patients in our outpatient chemotherapy clinic.

Antiemetic medication was carried out according to the Japanese Society of Clinical Oncology (JSCO) clinical practice guideline for antiemesis, in which the combination of $5-\mathrm{HT}_{3}$ receptor antagonist such as intravenous granisetron (3mg) and intravenous dexamethasone $(9.9 \mathrm{mg})$ was prescribed before chemotherapy for prevention of acute CINV, and oral dexamethasone (4-8mg/day) was administered on days 2 and 3 of chemotherapy for prophylaxis of delayed CINV in the first cycle of chemotherapy. In patients who experienced CINV in the previous cycle, antiemetic drugs with different mode of action, including aprepitant [11], olanzapine [12] or benzodiazepines [13], were added to the standard antiemetic medication on the next course of chemotherapy.

\section{Evaluation of the control of CINV}

Patients were all provided with a checklist for daily check of CINV on the first visit of outpatient chemotherapy clinic. Using the checklist, patients checked daily the nausea by numeric scale (NRS: 0-10) and the number of vomiting episodes up to 7 days after chemotherapy. Pharmacists had an interview to all patients who visited to our outpatient chemotherapy clinic and asked the presence or absence of CINV, regardless of whether patients filled the checklist of adverse drug reactions, including CINV. The control of nausea and vomiting was recorded on the electric medical record after verifying them or hearing from patients on the next visit. Complete inhibition of nausea (NRS scale < 1) and vomiting (no episode) during acute (within 24 hours after chemotherapy) and delayed (during 2-7 days after chemotherapy) periods was assessed in patients receiving the first cycle of chemotherapy or in those with overall cycles of chemotherapy. In our outpatient chemotherapy setting, on-demand use of antiemetic medication was not prescribed in most cases, therefore, the present data were devoid of information about rescue treatment. Thus, the primary endpoint was complete inhibition of nausea/vomiting rather than complete response or complete protection.

\section{Statistical analyses}

Data were analyzed using IBM SPSS Statistics ver. 22 (IBM Japan Services Co., Ltd., Tokyo, Japan). Patients' demographics were compared among groups with different MEC regimens by one-way analysis variance (ANOVA) followed by Scheffe's test for parametric variables, and by Kruscal-Wallis test followed by Scheffe's test for non-parametric variables. P value of less than 0.05 was considered statistically significant.

\section{Ethical considerations}

The present study was carried out in accordance with the guidelines for the care for human study adopted by the Ethics Committee of the Gifu Graduate School of Medicine, and notified by the Japanese 
Government (approved no. 26-153 of the Institutional Review Board).

\section{Results}

\section{Demographics of patients}

As shown in Table 1, 326 patients received 2,061 chemotherapy cycles from January 2013 to December 2014 in our outpatient chemotherapy clinic. The most common type of cancer was colorectal cancer (51.8\%), followed by lung cancer, and gynecologic cancer. The most frequently used anticancer drugs was oxaliplatin $(39.9 \%)$, followed by irinotecan, and carboplatin, while the most prevalent chemotherapy regimen for overall cycles was FOLFIRI (29.1\%), followed by mFOLFOX6, XELOX, and paclitaxel + carboplatin.

Table 1. Patient Demographics.

\begin{tabular}{|c|c|c|c|c|}
\hline \multicolumn{2}{|l|}{ Number of patients (male/female) } & \multicolumn{3}{|c|}{ [174 / 152] } \\
\hline & \multicolumn{4}{|l|}{$n$} \\
\hline Overall chemotherapy cycles & \multicolumn{4}{|l|}{2,061} \\
\hline First cycle & \multicolumn{4}{|l|}{201} \\
\hline Age $^{a}$ & 62.5 & \multicolumn{3}{|l|}{ [18 - 85] } \\
\hline Height $(\mathrm{cm})^{\mathrm{b}}$ & 160.7 & \multicolumn{3}{|l|}{ \pm 8.6} \\
\hline Body weight $(\mathrm{kg})^{\mathrm{b}}$ & 57.2 & \multicolumn{3}{|l|}{ \pm 11.0} \\
\hline Body surface area $\left(\mathrm{m}^{2}\right)^{\mathrm{b}}$ & 1.59 & \multicolumn{3}{|l|}{ \pm 0.17} \\
\hline Serum creatinine $(\mathrm{mg} / \mathrm{dL})^{\mathrm{b}}$ & 0.71 & \multicolumn{3}{|l|}{ \pm 0.21} \\
\hline Cancer type & $n$ & \multicolumn{3}{|l|}{$\%$} \\
\hline Colorectal cancer & 169 & \multicolumn{3}{|l|}{51.8} \\
\hline Lung cancer & 52 & \multicolumn{3}{|l|}{16.0} \\
\hline Gynecologic cancer & 34 & \multicolumn{3}{|l|}{10.4} \\
\hline Gastric cancer & 17 & \multicolumn{3}{|l|}{5.2} \\
\hline Head and neck cancer & 15 & \multicolumn{3}{|l|}{4.6} \\
\hline Breast cancer & 15 & \multicolumn{3}{|l|}{4.6} \\
\hline Hematological cancer & 12 & \multicolumn{3}{|l|}{3.7} \\
\hline \multirow[t]{2}{*}{ Others } & 12 & \multicolumn{3}{|l|}{3.7} \\
\hline & \multicolumn{2}{|c|}{ Patients } & \multicolumn{2}{|c|}{ Chemotherapy cycles } \\
\hline Chemotherapy regimens & $n$ & $\%$ & $n$ & $\%$ \\
\hline XELOX & 62 & 19.0 & 334 & 16.2 \\
\hline mFOLFOX6 & 47 & 14.4 & 452 & 21.9 \\
\hline PTX/CBDCA & 42 & 12.9 & 146 & 7.1 \\
\hline FOLFIRI & 32 & 9.8 & 600 & 29.1 \\
\hline PEM/CBDCA & 27 & 8.3 & 58 & 2.8 \\
\hline S-1/1-OHP & 20 & 6.1 & 92 & 4.5 \\
\hline СРТ-11 & 18 & 5.5 & 85 & 4.1 \\
\hline S-1/CPT-11 & 15 & 4.6 & 100 & 4.9 \\
\hline GEM/CBDCA & 14 & 4.3 & 38 & 1.8 \\
\hline DTX/CPA & 9 & 2.8 & 34 & 1.6 \\
\hline FOLFIRINOX & 8 & 2.5 & 37 & 1.8 \\
\hline Others & 32 & 9.8 & 85 & 4.1 \\
\hline Anticancer drugs & \multicolumn{2}{|c|}{ Patients } & \multicolumn{2}{|c|}{ Chemotherapy cycles } \\
\hline Oxaliplatin & 130 & 39.9 & 880 & 42.7 \\
\hline Carboplatin & 93 & 28.5 & 267 & 13.0 \\
\hline Irinotecan & 65 & 19.9 & 798 & 38.7 \\
\hline Cyclophosphamide & 18 & 5.5 & 52 & 2.5 \\
\hline Nedaplatin & 6 & 1.8 & 16 & 0.8 \\
\hline Others & 14 & 4.3 & 48 & 2.3 \\
\hline \multicolumn{5}{|c|}{$\begin{array}{l}\text { XELOX:capecitabine and oxaliplatin; mFOLFOX6: 5-fluorouracil, folinic acid, and } \\
\text { oxaliplatin; PTX: paclitaxel; CBDCA: carboplatin; FOLFIRI: 5-fluorouracil, folinic } \\
\text { acid, and irinotecan; PEM: pemetrexed; S-1: tegafur/ gimeracil/ oteracil; CPT-11: } \\
\text { irinotecan; GEM: gemcitabine; DTX: docetaxel; CPA: cyclophosphamide; } \\
\text { FOLFIRINOX: 5-fluorouracil, folinic acid, irinotecan, and oxaliplatin. a Values } \\
\text { shown as mean [renge]. b Values shown as meantstandard deviation. }\end{array}$} \\
\hline
\end{tabular}

\section{Control of CINV in the first cycle of MEC regimens}

As shown in Table 2, among 201 patients, all received single-day MEC in combination with ( $\mathrm{N}=192$, $95.5 \%)$ or without $(\mathrm{N}=9,4.5 \%)$ multiple treatment with either low emetic risk $(\mathrm{N}=191)$ or minimal risk $(\mathrm{N}=1,0.5 \%)$ chemotherapy agents. No multiple-day MEC regimens existed in the first cycle of the present study. Antiemetic premedication was carried out in $100 \%$ on day 1 and $87.6 \%$ on days $2-3$. The rate of complete inhibition of nausea and vomiting was $87.6 \%$ and $95.5 \%$, respectively, during acute period, while the rate was $68.2 \%$ and $92.0 \%$, respectively, during delayed period. As shown in Figure 1A, there were no significant differences in the control of nausea and vomiting during acute and delayed periods among carboplatin, irinotecan, and oxaliplatin, except for cyclophosphamide. The rates of complete inhibition of acute and delayed vomiting were significantly $(\mathrm{p}=0.017)$ lower in cyclophosphamide-base regimens $(\mathrm{n}=14)$, including cyclophosphamide $\left(600 \mathrm{mg} / \mathrm{m}^{2}\right)+$ docetaxel $\left(75 \mathrm{mg} / \mathrm{m}^{2}\right)$ for breast cancer $(\mathrm{n}=11)$, cyclophosphamide $\left(100 \mathrm{mg} / \mathrm{m}^{2}\right)+$ methotrexate $\left(40 \mathrm{mg} / \mathrm{m}^{2}\right)$ +5 -fluorouracil $\left(600 \mathrm{mg} / \mathrm{m}^{2}\right)$ for breast cancer $(\mathrm{n}=1)$ and cyclophosphamide $\left(600 \mathrm{mg} / \mathrm{m}^{2}\right)+$ vincristine $(1.5$ $\left.\mathrm{mg} / \mathrm{m}^{2}\right)$ for malignant lymphoma $(\mathrm{n}=2)$.

Table 2. Rate of Two-Drug Antiemetic Medication, Control of Nausea and Vomiting during Acute, Delayed and Overall Periods in Patients Receiving MEC.

\begin{tabular}{lll}
\hline & First cycle $(\mathrm{n}=201)$ & Overall cycles $(\mathrm{n}=2,061)$ \\
\hline Rate of antiemetic medication & $\%$ & $\%$ \\
Acute & 100 & 99.4 \\
Delayed & 87.6 & 82.7 \\
Overall & 87.6 & 82.4 \\
Complete protection from nausea & \\
Acute & 87.6 & 85.9 \\
Delayed & 68.2 & 73.7 \\
Overall & 66.2 & 72.4 \\
Complete protection from vomiting & \\
Acute & 95.5 & 97.5 \\
Delayed & 92.0 & 96.7 \\
Overall & 91.5 & 95.5 \\
\hline
\end{tabular}

Figure 1B shows a comparison of the rates of complete inhibition of nausea and vomiting during acute and delayed periods among respective MEC regimens, including oxaliplatin + capecitabine (XELOX) or TS-1 (SOX), modified FOLFOX6 (mFOLFOX6), FOLFIRI, carboplatin in combination with pemetrexed, gemcitabine, paclitaxel or docetaxel, and cyclophosphamide + docetaxel. The rates of complete inhibition of nausea and vomiting were almost similar among these regimens except for cyclophosphamide + docetaxel. The rates of complete inhibition of vomiting during acute and delayed peri- 
ods were significantly lower in cyclophosphamide + docetaxel than in other regimens, although the rates of complete inhibition of nausea tended to be lower in cyclophosphamide + docetaxel.

Table 3 shows the comparison of patients' demographics among MEC such as carboplatin, iri- notecan, oxaliplatin and cyclophosphamide. The percentage of female in irinotecan group was significantly lower than those in other groups. Moreover, patients receiving cyclophosphamide were significantly younger than those receiving other regimens.

A) Chemotherapy drugs

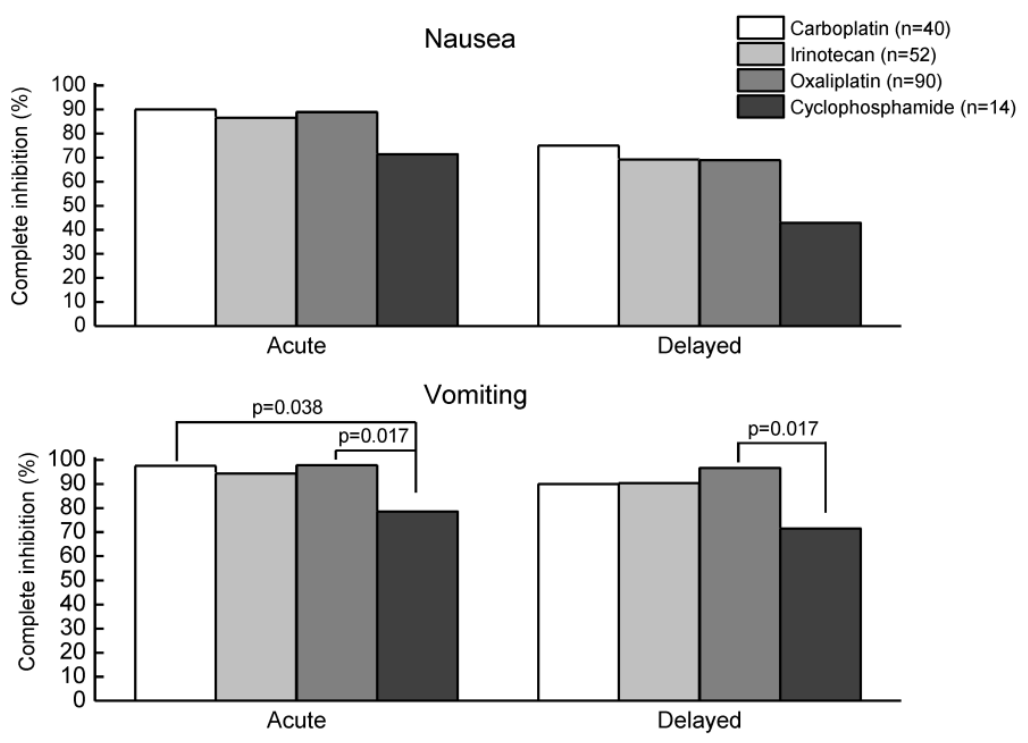

B) Chemotherapy regimens

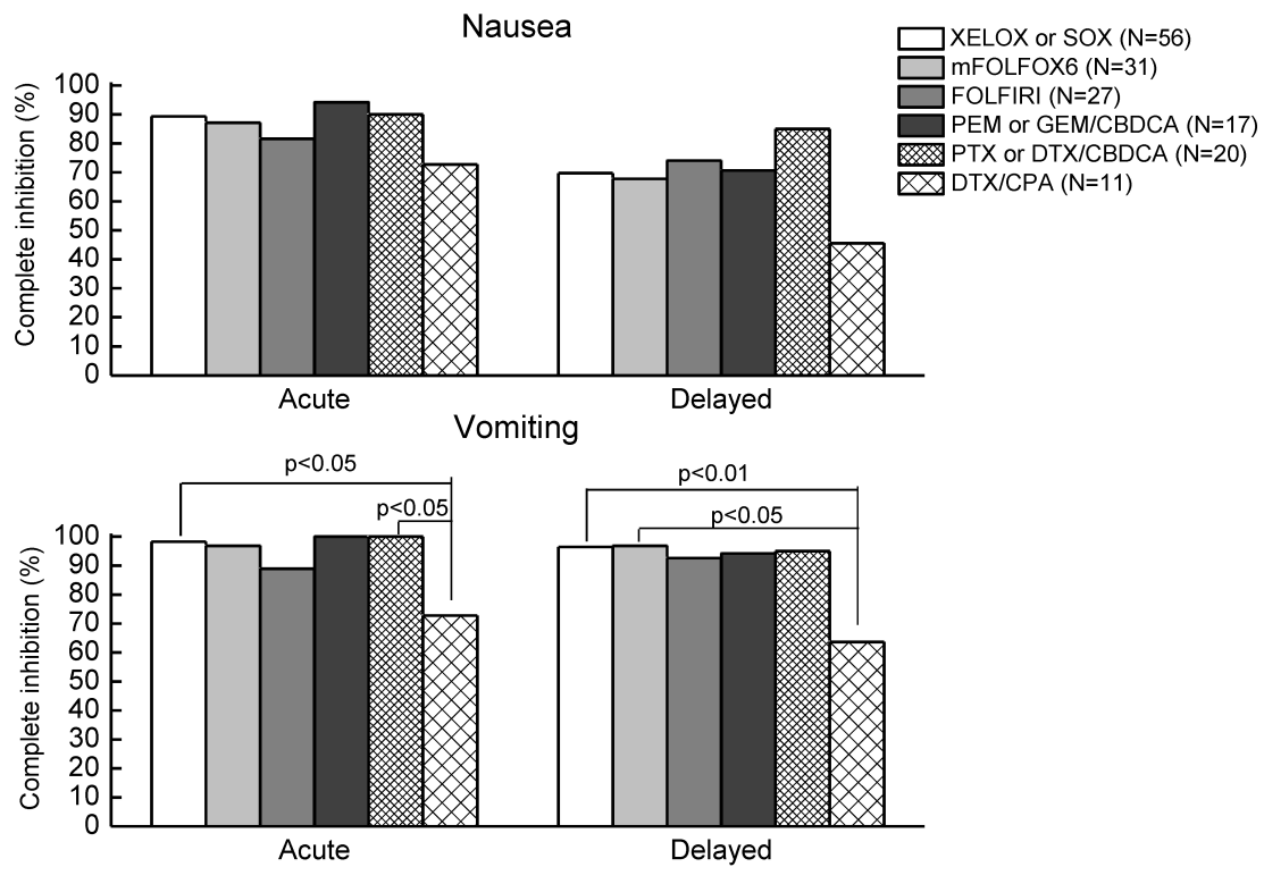

Figure 1. Comparison of the complete inhibition of nausea and vomiting during acute and delayed periods among various MEC drugs (A) and regimens (B) in patients receiving the first cycle of chemotherapy in the outpatient chemotherapy clinic. Data were statistically compared by Kruscal-Wallis test, followed by Scheffe's test. Abbreviations: XELOX or SOX (capecitabine $2,000 \mathrm{mg} / \mathrm{m}^{2}$, days $1-14$ or TS- $180 \mathrm{mg} / \mathrm{m}^{2}$, days $1-14+$ oxaliplatin $130 \mathrm{mg} / \mathrm{m}^{2}$, day 1 , every $3 \mathrm{weeks}$ ), mFOLFOX6: modified FOLFOX6 (5-fluorouracil $400 \mathrm{mg} / \mathrm{m}^{2}$, bolus infusion and $2,400 \mathrm{mg} / \mathrm{m}^{2}$, continuous infusion for $24 \mathrm{~h}+$ levofolinate $200 \mathrm{mg} / \mathrm{m}^{2}$, day 1 , bolus infusion + oxaliplatin $85 \mathrm{mg} / \mathrm{m}^{2}$, day 1 , every 2 weeks), FOLFIRI (5-fluorouracil $400 \mathrm{mg} / \mathrm{m}^{2}$, bolus infusion and $2,400 \mathrm{mg} / \mathrm{m}^{2}$, continuous infusion for $24 \mathrm{~h}+$ levofolinate $200 \mathrm{mg} / \mathrm{m}^{2}$, day 1 , bolus infusion + irinotecan $150 \mathrm{mg} / \mathrm{m}^{2}$, day 1 , every 2 weeks), PEM or GEM/CBDCA (pemetrexed $500 \mathrm{mg} / \mathrm{m}^{2}$, day 1 or gemcitabine $1,000 \mathrm{mg} / \mathrm{m}^{2}$, day $1,8+$ carboplatin $\mathrm{AUC}=5$, day 1 , every 3 weeks), PTX or DTX/CBDCA(paclitaxel $180-200 \mathrm{mg} / \mathrm{m}^{2}$, day 1 or docetaxel $75 \mathrm{mg} / \mathrm{m}^{2}$, day $1+$ carboplatin AUC=5, day 1 , every 3 weeks), DTX/CPA (docetaxel $75 \mathrm{mg} / \mathrm{m}^{2}$, day $1+$ cyclophosphamide $600 \mathrm{mg} / \mathrm{m}^{2}$, day 1 , every 3 weeks). 
Table 3. Comparison of Patient Demographics among Patients Receiving the First Cycle of MEC Regimen.

\begin{tabular}{|c|c|c|c|c|c|c|c|c|c|}
\hline \multirow[t]{2}{*}{ Anticancer drugs } & \multicolumn{3}{|c|}{ Gender } & \multicolumn{2}{|l|}{ Age } & \multicolumn{2}{|c|}{ Body surface area $\left(\mathrm{m}^{2}\right)$} & \multicolumn{2}{|c|}{ Serum creatinine $(\mathrm{mg} / \mathrm{dL})$} \\
\hline & male & female & Female (\%) & average & Min - max & average & $\pm \mathrm{SD}$ & average & $\pm \mathrm{SD}$ \\
\hline Carboplatin & 14 & 26 & 65.0 & 63.6 & $40-78$ & 1.58 & \pm 0.15 & 0.70 & \pm 0.19 \\
\hline Irinotecan & 41 & 11 & $21.2^{\mathrm{a}}$ & 66.8 & $35-85$ & 1.64 & \pm 0.18 & 0.79 & \pm 0.24 \\
\hline Oxaliplatin & 46 & 44 & 48.9 & 62.0 & $38-84$ & 1.60 & \pm 0.21 & 0.68 & \pm 0.21 \\
\hline Cyclophosphamide & 2 & 12 & 85.7 & $46.2^{b}$ & $18-74$ & 1.56 & \pm 0.10 & 0.54 & \pm 0.12 \\
\hline
\end{tabular}

a) $\mathrm{p}<0.01$ vs oxaliplatin, $\mathrm{p}<0.01$ vs carboplatin, cyclophosphamide by Kruscal-Wallis test followed by Scheffe's test;

b) $\mathrm{p}<0.01$ vs carboplatin, irinotecan, oxaliplatin by one-way ANOVA followed by Scheffe's test;

c) $\mathrm{p}<0.01$ vs irinotecan by one-way ANOVA followed by Scheffe's test.
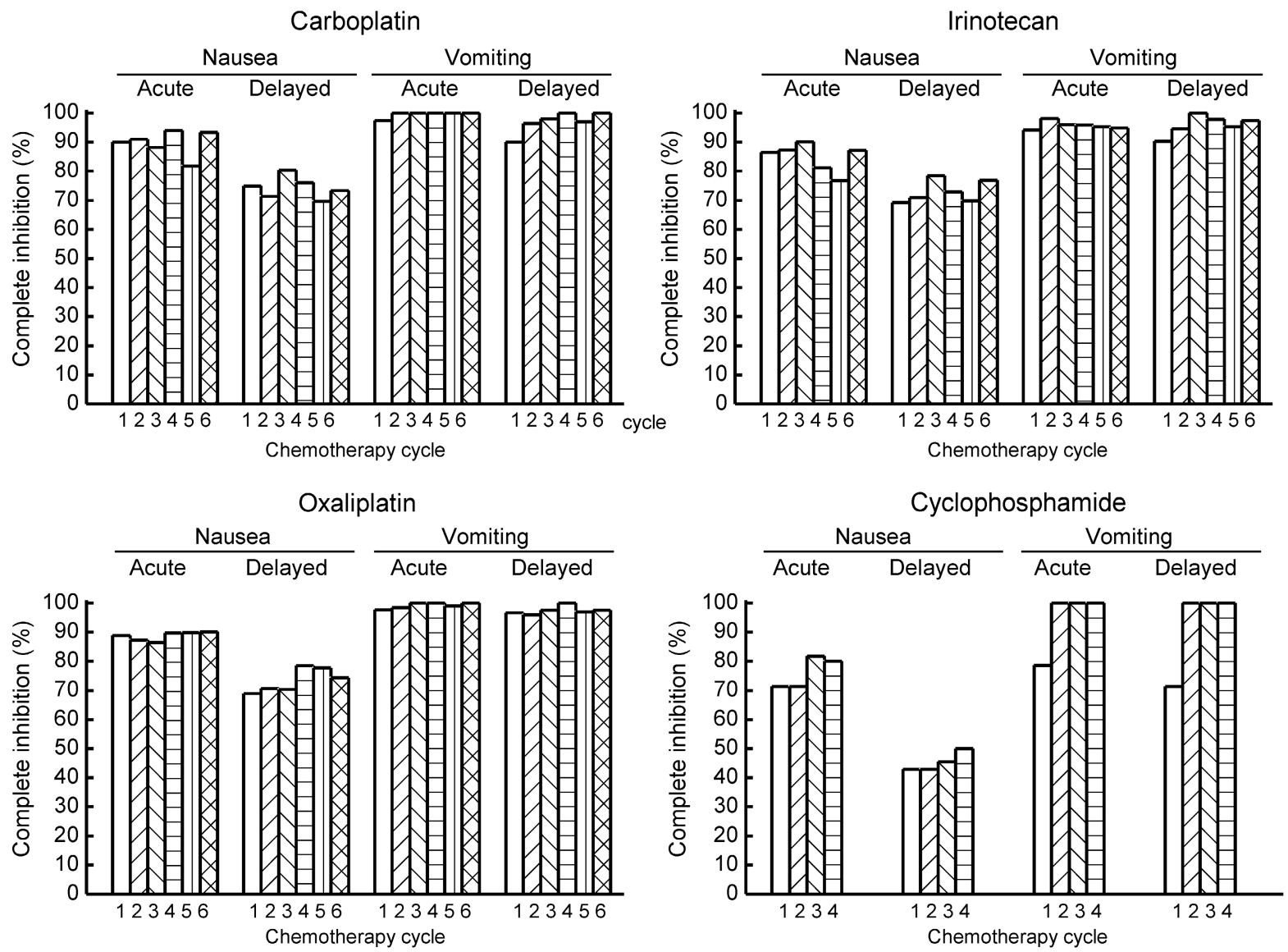

Figure 2. Comparison of the control of acute and delayed CINV among various MEC regimens in patients receiving the first to fourth or sixth cycle of chemotherapy in the outpatient chemotherapy clinic.

\section{Control of CINV in overall chemotherapy cy- cles}

Figure 2 shows the rates of complete inhibition of nausea and vomiting during acute and delayed periods in multiple chemotherapy cycles from the first to the sixth or fourth cycle. No marked differences in the control of nausea or vomiting were observed among cycles of any MEC regimen.

\section{Discussion}

In our outpatient chemotherapy clinic, pharmacists met with all patients and were in charge of monitoring of adverse events, including CINV, planning of preventive measures against adverse events, and verification of the prescription order regarding cancer chemotherapy regimens.

In the present study, the two-drug antiemetic medication of granisetron (day 1) and dexamethasone (days $1-3$ ) was prescribed in $87.6 \%$ and $82.4 \%$ of the first cycle and overall cycles, respectively. Under such conditions, the rates of complete inhibition of nausea and vomiting were $87.6 \%$ and $95.5 \%$, respectively, during acute period of the first chemotherapy cycle, and $68.2 \%$ and $92.0 \%$, respectively, during delayed period of the first cycle. Our data on the control of CINV were generally consistent with those reported by Escobar et al. [14], who showed in 240 chemo- 
therapy-naïve patients receiving MEC that the rates of complete inhibition of nausea and vomiting are $76.7 \%$ and $90.8 \%$, respectively, during acute period, and $61.5 \%$ and $83.5 \%$, respectively, during delayed period. The slightly higher rates of the control of CINV observed in the present study as compared with those reported by Escobar et al. [14] may be due to the higher prevalence rate of antiemetic medication in our study as compared with their data $(100 \%$ and $87.6 \%$ versus $94.9 \%$ and $43.8 \%$ during acute and delayed periods, respectively), since patients' demographics such as age, gender, proportion of colorectal cancer were similar between the two studies. It has been demonstrated that the control of CINV is significantly improved by adherence to the antiemetic guideline [6, $7,15]$.

It was notable that the control of CINV in the first cycle were similar among various MEC regimens, including carboplatin, irinotecan, and oxaliplatin. However, the control of CINV was worst in cyclophosphamide-base regimens, including predominantly docetaxel + cyclophosphamide for breast cancer, as compared with other regimens. The demographics of patients showed that the proportion of female was highest in cyclophosphamide-base regimens. Moreover, patients receiving cyclophosphamide-base regimens were significantly younger than those of any other group. It has been demonstrated that female and younger age are significant risks for developing CINV. Sekine et al. [16] reported in 1,549 patients receiving HEC or MEC that female is more likely to show a failure in complete response than male. Hilarius et al. [17] also showed in 225 patients receiving HEC or MEC that the incidence rates of acute and delayed nausea as well as vomiting are significantly higher in female than male. Younger age is also linked with higher incidence of CINV, although the cut-off value for age varied depending on each study ranging from 40-year-old [18] to 65-year old $[17,19]$. Therefore, it is suggested that such risk factors rather than cyclophosphamide itself might be involved in higher incidence of CINV in patients receiving cyclophosphamide-base regimens observed in the present study, although we could not exclude a possibility that cyclophosphamide is a high risk for CINV [20].

The control of CINV was similar or rather improved after multiple chemotherapy cycles from the first cycle to the sixth or fourth cycle. This may be due at least in part to the following reasons: antiemetic drugs with different mode of action such as olanzapine and aprepitant were added to the two-drug antiemetic regimen in the subsequent cycle in patients who experienced significant CINV in previous cycle. Indeed, among 35 patients showing significant CINV in the first cycle, 29 patients received subsequent chemotherapy cycles. Among 29 patients, 18 patients $(62.1 \%)$ were treated with additional antiemetic drugs, including aprepitant $(20.7 \%)$, olanzapine $(17.2 \%)$, and palonosetron (13.8\%). The incidence rates of grade $>2$ nausea and vomiting in the first cycle tended to be higher in the additional antiemetic drugs-treated group than non-treated group $(94.4 \%$ and $16.7 \%$ for nausea and vomiting, respectively, in additional antiemetic drugs-treated group versus $72.7 \%$ and $0 \%$, respectively, in non-treated group). The rate of complete inhibition of nausea and vomiting during overall period was improved from $0 \%$ in the first cycle to $22.2 \%$ in the subsequent cycle with additional antiemetic drugs, although the rate was also elevated from $0 \%$ to $18.2 \%$ in the subsequent course without additional antiemetic medication.

Aprepitant is known to be highly effective for prevention of vomiting [11] but to a lesser extent for the prophylaxis of nausea [21]. On the other hand, it has been reported that olanzapine, atypical antipsychotics agent, is more potent than aprepitant in preventing chemotherapy-induced nausea [12]. This may be due to the binding profile of olanzapine showing affinity for a variety of neurotransmitter receptors, including it only dopamine $\mathrm{D}_{2}$ receptors but also $5-\mathrm{HT}_{2 \mathrm{~B}}$ and $5-\mathrm{HT}_{2 \mathrm{C}}$ receptors [22] that control the secretion of ghrelin [23], an appetite-promoting hormone. Therefore, aprepitant was added in patients who experienced vomiting, while olanzapine was included in case nausea was not controlled in the previous cycle.

Taken together, it is suggested that two-drug antiemetic medication including $5-\mathrm{HT}_{3}$ receptor antagonist and dexamethasone is enough to prevent CINV in patients receiving MEC other than docetaxel/cyclophosphamide regimen for breast cancer, in which three-drug antiemetic medication is required. However, aprepitant or olanzapine may be added to the two-drug regimen in patients with high risk of CINV, including younger age and female, or in those who did not control CINV in the previous cycle, as indicated by the NCCN 2015 guideline.

There are several limitations in the present study. First, the present study was a non-randomized single-center study. Second, the small number of chemotherapy naïve patients were enrolled and the number of patients in each MEC regimen was so small as to clearly demonstrate the necessity of aprepitant in the specific MEC regimens. Third, gastrointestinal cancers such as colorectal cancer and stomach cancer were predominant (approximately $60 \%$ of all patients), therefore, limited range of anticancer drugs were used in the present study. Fourth, complete response, one of most common indices of the control of 
CINV, was not included in the present study because of the difficulty in obtaining data on the rescue treatment from the outpatient setting.

In conclusion, two-drug antiemetic regimen showed favorable control for most of the cases underwent MEC, however, more intensive supportive care might be necessary, especially for controlling nausea, in some of the patients or in some of the chemotherapy regimens.

\section{Competing Interests}

The authors have declared that no competing interest exists.

\section{References}

1. Sun CC, Bodurka DC, Weaver CB, et al. Rankings and symptom assessments of side effects from chemotherapy: insights from experienced patients with ovarian cancer. Support Care Cancer. 2005; 13: 219-27.

2. Basch E, Prestrud AA, Hesketh PJ, et al. American Society of Clinical Oncology. Antiemetics: American Society of Clinical Oncology clinical practice guideline update. J Clin Oncol. 2011; 29: 4189-98.

3. Roila F, Herrstedt J, Aapro M, et al. ESMO/MASCC Guidelines Working Group. Guideline update for MASCC and ESMO in the prevention of chemotherapy- and radiotherapy-induced nausea and vomiting: results of the Perugia consensus conference. Ann Oncol. 2010; 21 Suppl 5: v232-43.

4. National Comprehensive Cancer Network (NCCN). Clinical Practice Guidelines in Oncology (NCCN Guidelines $\left.{ }^{\circledR}\right)$. Antiemesis Version 1.2015: http://www.nccn.org/professionals/physician gls/pdf/antiemesis.pdf

5. Takeuchi H, Saeki T, Aiba K, et al. Japanese Society of Clinical Oncology clinical practice guidelines 2010 for antiemesis in oncology: executive summary. Int J Clin Oncol. 2015: in press, doi 10.1007/s10147-015-0852-1.

6. Aapro M, Molassiotis A, Dicato M, et al. PEER investigators. The effect of guideline-consistent antiemetic therapy on chemotherapy-induced nausea and vomiting (CINV): the Pan European Emesis Registry (PEER). Ann Oncol. 2012; 23: 1986-92.

7. Gilmore JW, Peacock NW, Gu A, et al. Antiemetic guideline consistency and incidence of chemotherapy-induced nausea and vomiting in US community oncology practice: INSPIRE Study. J Oncol Pract. 2014; 10: 68-74.

8. Roscoe JA, Heckler CE, Morrow GR, et al. Prevention of delayed nausea: a University of Rochester Cancer Center Community Clinical Oncology Program study of patients receiving chemotherapy. J Clin Oncol. 2012; 30: 3389-95.

9. Farrell C, Brearley SG, Pilling M, et al. The impact of chemotherapy-related nausea on patients' nutritional status, psychological distress and quality of life. Support Care Cancer. 2013; 21: 59-66.

10. Rapoport BL, Jordan K, Boice JA, et al. Aprepitant for the prevention of chemotherapy-induced nausea and vomiting associated with a broad range of moderately emetogenic chemotherapies and tumor types: a randomized, double-blind study. Support Care Cancer. 2010; 18: 423-31.

11. Navari RM, Reinhardt RR, Gralla RJ, et al. Reduction of cisplatin-induced emesis by a selective neurokinin-1-receptor antagonist. L-754,030 Antiemetic Trials Group. N Engl J Med. 1999; 340: 190-5.

12. Navari RM, Gray SE, Kerr AC. Olanzapine versus aprepitant for the prevention of chemotherapy-induced nausea and vomiting: A randomized phase III trial. J Support Oncol. 2011; 9: 188-95.

13. Kamen C, Tejani MA, Chandwani K, et al. Anticipatory nausea and vomiting due to chemotherapy. Eur J Pharmacol. 2014; 722: 172-9.

14. Escobar Y, Cajaraville G, Virizuela JA, et al. Incidence of chemotherapy-induced nausea and vomiting with moderately emetogenic chemotherapy: ADVICE (Actual Data of Vomiting Incidence by Chemotherapy Evaluation) study. Support Care Cancer. 2015; 23: 2833-40.

15. Fujii $H$, Iihara $H$, Ishihara $M$, et al. Improvement of adherence to guidelines for antiemetic medication enhances emetic control in patients with colorectal cancer receiving chemotherapy of moderate emetic risk. Anticancer Res. 2013; 33: 5549-56.

16. Sekine I, Segawa Y, Kubota K, et al. Risk factors of chemotherapy-induced nausea and vomiting: index for personalized antiemetic prophylaxis. Cancer Sci. 2013; 104: 711-7.

17. Hilarius DL, Kloeg PH, van der Wall E, et al. Chemotherapy-induced nausea and vomiting in daily clinical practice: a community hospital-based study. Support Care Cancer. 2012; 20: 107-17.

18. Booth CM, Clemons M, Dranitsaris G, et al. Chemotherapy-induced nausea and vomiting in breast cancer patients: a prospective observational study. J Support Oncol. 2007; 5: 374-80.

19. Hesketh PJ, Aapro M, Street JC, et al. Evaluation of risk factors predictive of nausea and vomiting with current standard-of-care antiemetic treatment: analysis of two phase III trials of aprepitant in patients receiving cisplatin-based chemotherapy. Support Care Cancer. 2010; 18: 1171-7.

20. Jones SE, Savin MA, Holmes FA, et al. Phase III trial comparing doxorubicin plus cyclophosphamide with docetaxel plus cyclophosphamide as adjuvant therapy for operable breast cancer. J Clin Oncol. 2006; 24: 5381-7.

21. Rapoport BL, Jordan K, Boice JA, et al. Aprepitant for the prevention of chemotherapy-induced nausea and vomiting associated with a broad range of moderately emetogenic chemotherapies and tumor types: a randomized, double-blind study. Support Care Cancer. $2010 ; 18: 423-431$

22. Shahid M, Walker GB, Zorn SH, et al. Asenapine: a novel psychopharmacologic agent with a unique human receptor signature. J Psychopharmacol. 2009; 23: 65-73.

23. Takeda H, Sadakane C, Hattori T, et al. Rikkunshito, an herbal medicine, suppresses cisplatin-induced anorexia in rats via 5-HT2 receptor antagonism. Gastroenterology. 2008; 134: 2004-13. 